\title{
The role of ultrasonically induced acoustic streaming in developing fine equiaxed grains during the solidification of an $\mathrm{Al-2 \%} \mathrm{Cu}$ alloy
}

Eskin $^{5,6}$, Matthew S. Dargusch ${ }^{1,2}$, David H. StJohn ${ }^{1,2}$

${ }^{1}$ Centre for Advanced Materials Processing and Manufacturing, The University of Queensland, St Lucia, Queensland, 4072, Australia

${ }^{2}$ Defence Materials Technology Centre (DMTC), The University of Queensland, St Lucia, QLD 4072 Australia

${ }^{3}$ School of Metallurgical Engineering, Xi'an University of Architecture and Technology, Xi'An, Shaanxi 710055, China

${ }^{4}$ Centre of Additive Manufacturing, School of Engineering, RMIT University, Melbourne, VIC 3000, Australia

${ }^{5}$ Brunel Centre for Advanced Solidification Technology (BCAST), Brunel University London, Uxbridge UB8 3PH, U.K.

${ }^{6}$ Tomsk State University, Tomsk, 634050 Russia

\section{Abstract}

Recent research and a simulation of heat transfer and solidification during acoustically generated convection showed that the location of the coolest liquid, and thus the place where the first grains are expected to form, is under the sonotrode. Further, the generated vigorous convection produces a very flat temperature gradient in the bulk of the melt facilitating the formation of a refined equiaxed structure throughout the casting. This study validates these findings through a series of experiments on an $\mathrm{Al}-2 \mathrm{wt} \% \mathrm{Cu}$ alloy, that evaluate grain formation under the sonotrode over time and relates this to the formation of the macrostructure of a cast ingot. Analysis of the results confirms the predictions of the simulation and shows, for the conditions applied, that most grains nucleated in the cavitation zone are swept into the melt by acoustically generated convection and over a period of 70 seconds the number of grains increase and they grow with spherical and globular morphology gradually filling the casting with refined equiaxed grains. It was found that the macrostructure of each casting is made up of three microstructural zones. A fine grained equiaxed zone forms from the bottom of the casting below the sonotrode due to settling of grains during and after termination of ultrasonic treatment (UST), which increases in size with increasing duration of UST. Above this zone a coarse grained structure is formed due to depletion of UST-generated grains on termination of UST. At the top of the casting a zone of columnar grains growing from the top surface of the melt is formed. The latter two zones decrease in size with increasing UST duration until 80 seconds where the macrostructure consists entirely of the equiaxed zone. 
Key words: aluminium alloy, grain refinement, acoustic streaming, ultrasonic treatment

\section{Introduction}

Application of high intensity ultrasound to the processing of metallic melts has attracted research interest for many years as summarized in monographs [1,2]. In the last two decades there has been a revival of interest in studying the fundamentals and to develop technologically viable methods of implementing ultrasonic melt processing in industrial casting processes. To date, ultrasound has been well demonstrated at the laboratory scale to refine a broad range of metals and alloys including $\mathrm{Mg}$ alloys [3, 4], Al alloys [1, 3, 5-7], steel [2, 8, 9], Zn [10], and a TiAl alloy [11].

The influence of ultrasonication on the refinement of microstructure is based on the physical phenomena caused by high intensity ultrasound propagation in the melt, in particular acoustic cavitation and acoustic streaming [1-3]. Although it has been recognized that acoustic streaming plays an important role in many ultrasound-assisted industrial processes including degassing, melt cleaning, homogenization, filtration and waste treatment $[12,13]$, it has not received as much attention as cavitation. Previous studies have dealt with the immediate effect of the collapse of the cavities or bubbles but overlooked the effect of acoustic streaming on solidification and grain formation. The lack of focus on acoustic streaming may explain why the exact mechanisms of UST refinement are still being debated $[7]$.

It has been reported that acoustic streaming generates convection with typical velocities in the range $0.2-0.8 \mathrm{~m} / \mathrm{s}$ with rapid attenuation as the distance from the ultrasonic source increases [14-19]. Acoustic streaming assists in equilibration of the temperature field in the liquid phase and interacts with the solidification front when the freezing range is wide [15]. Recent research highlighted the effect of acoustic streaming in generating convection patterns that facilitate the formation of refined equiaxed zones [20]. It also showed that, for ingots the same size as those used in the current study, when UST is applied the cooling curves from near the wall and towards the centre of an ingot converge to within $1{ }^{\circ} \mathrm{C}$ of each other.

To gain better understanding of the relationship between acoustic streaming, thermal equilibration and solidification, a simulation model was developed that simulates the effect of ultrasonic treatment (UST) on acoustic streaming $[15,21]$ by assuming that the volume under the sonotrode tip is a source of momentum that accelerates the surrounding fluid downwards forming a jet based on the equations developed by Lighthill [22]. The model is able to predict 
changes in convection patterns, velocity and temperature profiles generated thoughout an ingot during acoustic streaming and solidification. Very good correspondence between experimentally measured and simulated cooling curves was obtained [15, 21]. Figure 1 shows simulated temperature profiles when UST is not applied (Figure 1a) and while UST is being applied (Figure 1b). When UST is applied the temperature gradient is very low compared to the case without UST, and after UST is terminated a normal casting temperature profile with a steeper temperature gradient is established. This quasi steady state created by UST during cooling and nucleation of grains shows that the melt directly under the sonotrode is slightly cooler than the bulk of the melt where the temperature gradient is very flat [15]. Given that the melt is rapidly circulating under the sonotrode it would be expected that the temperature under the sonotrode would be very close to the melt temperature. It has been suggested that this condition where the ultrasound waves are at their most intense, is perfect for producing a fine grain size as this is where cavitation occurs and acoustic streaming is generated [15, 23]. Once the grains are formed, acoustically generated convection transports them into melt of a similar temperature and amount of undercooling which allows the grains to move without the risk of remelting $[15,20]$ thus favoring the formation of an equiaxed grain structure. Therefore, it was concluded that the convective flow induced by acoustic streaming plays a critical role in promoting nucleation, growth, grain survival and their transport. However, it should be noted that convection is dampened as the solid fraction increases, and could not be maintained in the simulation once the solid fraction exceeded approximately $21 \%$, the coherency point $[21,24]$. There are several types of coherency during solidification: dendritic, globular, maximum packing fraction and tensile coherency [25]. For this work we are referring to the morphological coherency: dendritic (where coherency occurs at a low solid fraction) or globular (at higher solid fraction) which represents the point when the grains begin to touch each other but are still not bonded together (i.e. the grains can still move relative to each other). The smaller and rounder the grain size the greater the value of coherency solid fraction. The value of $21 \%$ is the solid fraction after which computer modelling showed that convection could no longer be maintained. Research has shown that for large dendritic grains the morphological coherency point would be at $10 \%$ and for small globular grains it could be as high as $45 \%$. Thus, $21 \%$ indicates the situation for small dendrites and/or medium sized globular grains.

The current work seeks to validate the model and to better understand the role of UST during and after the nucleation stage on grain formation and microstructural refinement and 
to identify the physical phenomena involved during solidification of an Al-2 wt\% $\mathrm{Cu}$ alloy.

104 The role of acoustic streaming and the development of solid fraction in the formation of the 105 final grain structure are also discussed.

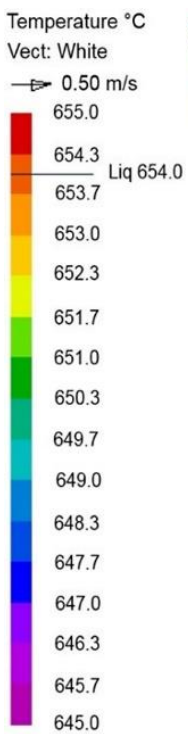

ProCAST

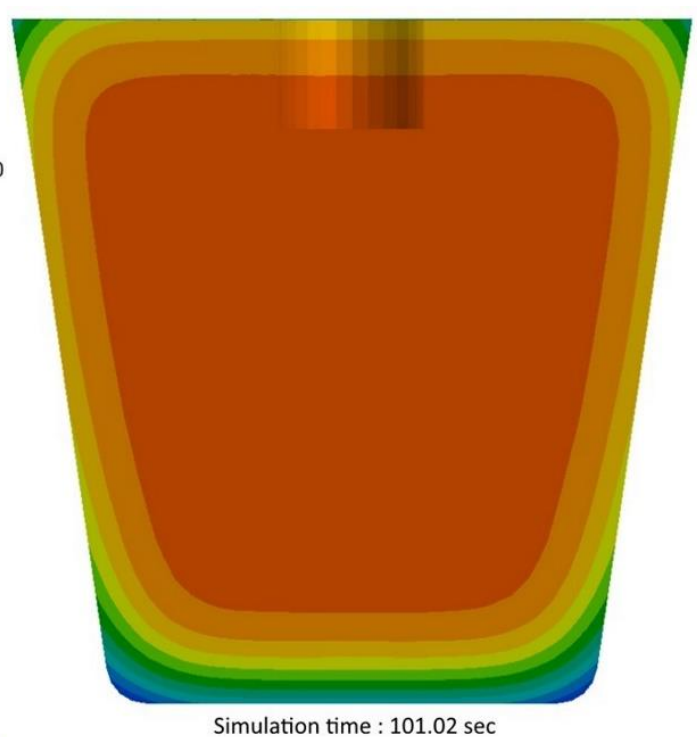

(a) Fraction solid $11.0 \%$

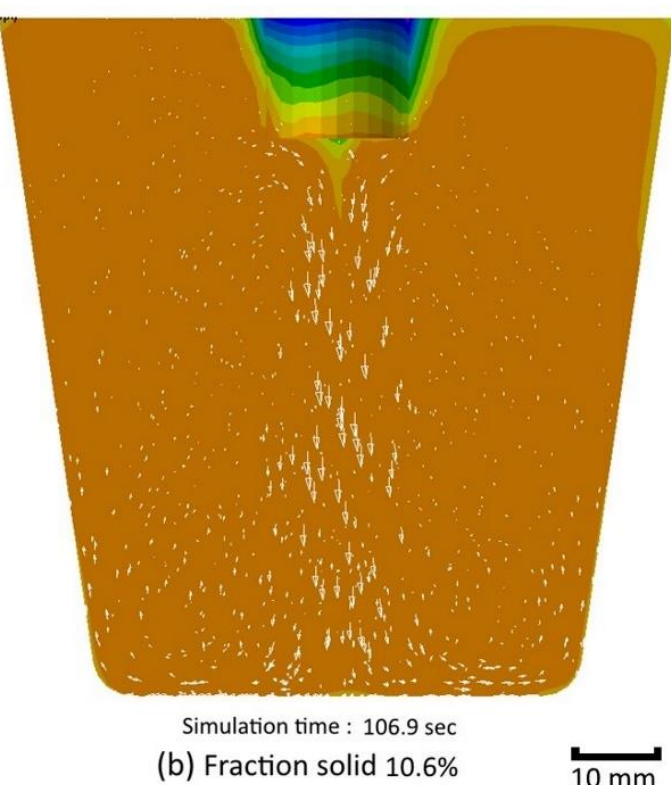

107 Figure 1. Simulated chill effect of the cold sonotrode on the melt temperature distribution at a simulation time of (a) $101 \mathrm{sec}$ without UST and (b) $107 \mathrm{sec}$ with UST, adapted from ref [15].

\section{Materials, experimental methods and experimental design}

An aluminium alloy with $2 \% \mathrm{Cu}$ (compositions are in wt $\%$ ) was produced in an electric melting furnace from $99.7 \%$ commercially pure aluminium and $99.9 \%$ pure copper. The

113 liquidus and solidus temperatures measured using differential thermal analysis (DTA-TG) and the chemical composition measured by spectral analysis of the alloy are presented in Table 1 . The temperatures were measured with an accuracy of $0.5^{\circ} \mathrm{C}$ and the composition is accurate to 5 rel.\%.

117 Table 1. Liquidus and solidus temperatures, and chemical composition of the $\mathrm{Al}-2 \% \mathrm{Cu}$ alloy.

\begin{tabular}{cccccccc}
\hline Liquidus $\left({ }^{\circ} \mathrm{C}\right)$ & Solidus $\left({ }^{\circ} \mathrm{C}\right)$ & \multicolumn{4}{c}{ Chemical composition (wt\%) } \\
\hline \multirow{2}{*}{655} & \multirow{2}{*}{620} & $\mathrm{Al}$ & $\mathrm{Cu}$ & $\mathrm{Si}$ & $\mathrm{Fe}$ & $\mathrm{Ti}$ \\
\cline { 3 - 8 } & & & $\mathrm{Bal}$ & 2.02 & 0.03 & 0.09 & $<0.01$ \\
\hline
\end{tabular}


The ultrasonic device used in this work consists of a $2 \mathrm{~kW}$ commercial ultrasound generator, an air cooled $20 \mathrm{kHz}$ transducer, and a sonotrode made of molybdenum based alloy with a tip $18 \mathrm{~mm}$ in diameter. About $1 \mathrm{~kg}$ of the alloy was melted inside a graphite-clay crucible with dimensions $90 \mathrm{~mm}$ top diameter, $60 \mathrm{~mm}$ bottom diameter and $120 \mathrm{~mm}$ in height. When the melt temperature reached $720 \pm 5^{\circ} \mathrm{C}$ the crucible was removed from the electric furnace and transferred to the experimental platform, which consists of the ultrasonic device with an air cooling unit, a refractory brick for seating the hot crucible, a sonotrode lifting unit, and a data acquisition system as illustrated in [26]. When the melt temperature reached $695^{\circ} \mathrm{C}$ which is $40^{\circ} \mathrm{C}$ above the liquidus temperature, the powered sonotrode without preheating was immersed into the melt to about $15 \mathrm{~mm}$ below the top surface of the melt. The UST experiments were conducted with a fixed $1 \mathrm{~kW}$ input power. UST was terminated by removing the powered sonotrode and then turning it off. Two K-type thermocouples were inserted into the melt to one side of the ultrasonic probe. One was close to the edge of the melt volume adjacent to the wall of the crucible and the other was $12.5 \mathrm{~mm}$ from the wall, with both thermocouples placed $45 \mathrm{~mm}$ above the bottom of the crucible as indicated in Figure $2 \mathrm{a}$. The temperature data was collected by a data-acquisition system with a sampling rate of 4 readings per second.

Three experiments were undertaken to provide information about the source of the equiaxed grains (i.e. the location of the nucleation events), their transport into the bulk of the melt, evolution of the micro and macro structures, and the morphology of the grains.

The first set of experiments was designed to confirm the location of the source of nucleation of equiaxed grains and the convective flow generated by acoustic streaming for the conditions used in this study. A gauze barrier has been used to isolate solidifing volumes for many decades to determine the origin of the equiaxed zone [27-30] and the location where new grains are nucleated [29-31]. Yin et al used this technique to confirm that nuclei dissociate from the mould wall with and without the application of electric current pulses [30], and $\mathrm{Li}$ et al used the same method to investigate the origin of grains of an AZ80 Mg alloy under a low voltage pulsed magnetic field [33]. Gauze sheets were constructed to isolate the liquid under the sonotrode as illustrated in Figure $2 \mathrm{~b}$. The melt was then cooled with the sonotrode turned on for 4 min after which it was removed from the solidifying melt as described above. The macrostructure was then evaluated. In addition, a glycerine-sand anologue was subjected to similar UST conditions to that applied in the following experiments to highlight the formation of convection due to acoustic streaming (Figure 2c). 
153 Although glycerine is more viscous than liquid aluminium and thus the degree of cavitation and streaming will be different [34], it is likely a similar pattern of convection will be induced as indicated by the simulation [15].

In the second series of experiments the evolution of grains under the sonotrode was investigated by inserting a small $5 \mathrm{~mm}$ diameter silica tube of $1 \mathrm{~mm}$ wall thickness into the melt to draw hot samples from under the sonotrode at a depth close to the position of the thermocouple nearest to the sonotrode (Figure 2a), followed by quenching the sample into cold water. Prior to inserting the tube into molten aluminium, it was preheated to $300^{\circ} \mathrm{C}$ to keep the tube dry and moisture free to avoid a violent moisture reaction with molten aluminium. It was expected that on insertion into the melt, the tube would quickly increase in temperature due to heat transfer from the surrounding melt. Some nucleation may be triggered by the relatively cold tube but this would be small compared to the total amount of nucleation that contributes to the the final grain size, and similar for each sample such that the measured trends would be unaffected. The time between filling and quenching was less than 2 seconds so any drop in temperature would be considered to be part of the quenching process. There was no observable reaction between the melt and the silica tube and the sample was readily removed after quenching. The samples were taken during UST at 0,10 , 20, 40, 60 and $80 \mathrm{~s}$ after the measured melt temperature reached $655^{\circ} \mathrm{C}$. The sampling points are indicated on the cooling curve shown in Figure $2 d$ to indicate the order in which the samples were extracted by the silica tube. Recalescence would be occurring while the first and second samples were extracted. Figures $2 \mathrm{~d}$ and e show that despite the temperature fluctuating during solidification the undercooling remains within $2^{\circ} \mathrm{C}$ below the liquidus temperature. This condition facilitates further nucleation and the survival, movement and growth of grains [23] while a large amount of liquid (> 75\%, as determined by Thermocalc) is present for the length of time that UST was applied.

In the third series of experiments the evolution of the macrostructure of the cast ingots was studied. For each test aproximately $1 \mathrm{~kg}$ of alloy was melted in the crucible and then the activated sonotrode was applied without preheating, from $695^{\circ} \mathrm{C}$ and terminated after 10,20 , 40 and $80 \mathrm{~s}$ (as shown in Figure 2e) by removing the sonotrode and turning off the ultrasonic power to allow the melt to solidify. After growth of the newly formed grains that occurs during UST, solidification continues as the melt cooled in air until solidification was complete below the solidus temperature. Previous work $[15,20]$ showed that a superheat of 
crystals formed on immersion of the cold sonotrode before solidification began. The final ascast grain structure was then examined.

Metallographic samples for ingots were sectioned along the central symmetrical axis, mechanically ground and polished using standard metallographic equipment for observation. Macroetching was done using a solution of hydrofluoric, nitric and hydrochloric acids. In order to measure the grain size, small samples were cut at $45 \mathrm{~mm}$ (the same height as the thermocouples) from the bottom of the sectioned piece. Tube samples were cold mounted in resin moulds, ground and polished along the axial direction axis. For both tube and ingot samples, micrographs were obtained using a Leica Polyvar microscope with polarized light after anodizing using a $0.5 \% \mathrm{HBF}_{4}$ water solution for about 20 seconds at $30 \mathrm{VDC}$. The number of spherical/globular equiaxed grains in the tube's total longitudinal cross section were manually counted. This number was converted to grain density per $\mathrm{cm}^{-3}$. The grain size was measured using the linear intercept method (ASTM E112-10). Statistical analysis of the results was performed. In order to understand the relationship between temperature and solid fraction during the solidification process, DTA-TG curves were obtained using a Netzsch STA $449 \mathrm{C}$ at a cooling rate of $10-20{ }^{\circ} \mathrm{C} / \mathrm{min}$ which is a slower cooling rate than that of the cast sample cooled in the ingot crucible which had a cooling rate of $30-40^{\circ} \mathrm{C} / \mathrm{min}$ above the liquidus temperature.

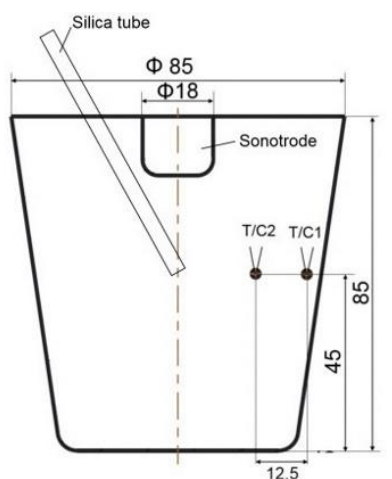

(a)

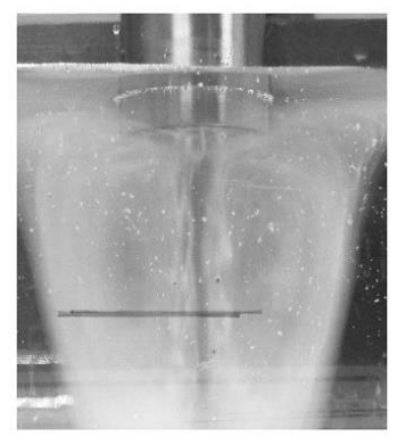

(c)
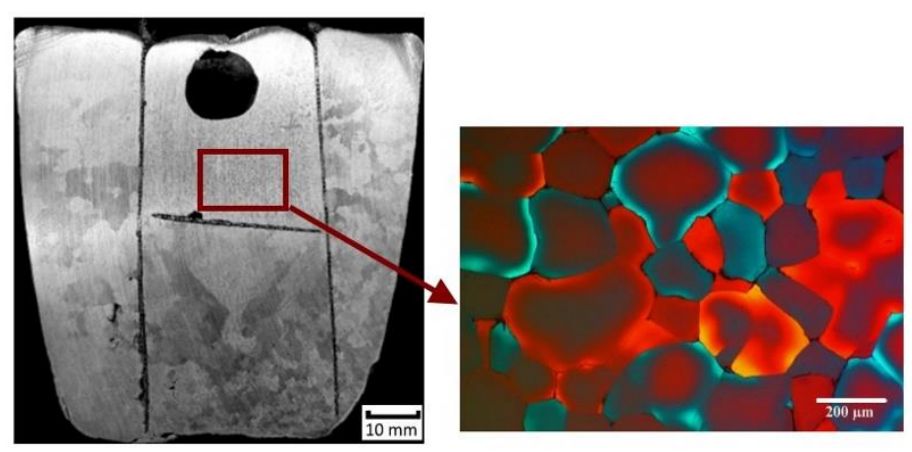

(b)

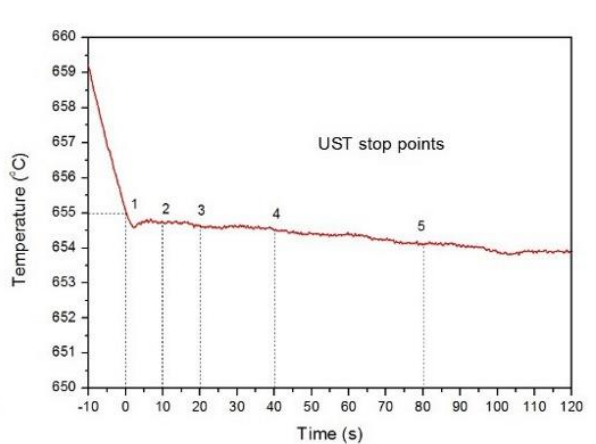

(e)

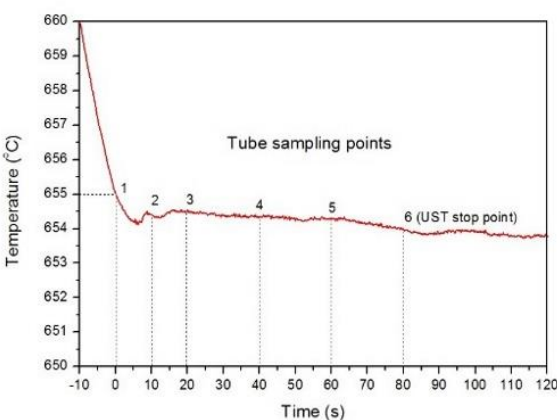

(d) 
Figure 2. (a) Schematic of a cast ingot indicating the internal dimensions of the casting cavity, the location of the ultrasonic probe (sonotrode), thermocouples and the tube for collecting samples of the semisolid alloy from under the sonotrode; (b) maco- and microstructure obtained from a gauze experiment to isolate the source of equiaxed grains (the large pore formed when the sonotrode was removed for the ingot); (c) acoustic streaming observed upon UST of glycerine; (d) a cooling curve highlighting the times when sampling occured during UST applied from $695^{\circ} \mathrm{C}$ for different durations measured from the time the melt reached the liquidus $\left(655^{\circ} \mathrm{C}\right.$ ) at $0 \mathrm{~s}$ (sample 1), $10 \mathrm{~s}$ (sample 2), $20 \mathrm{~s}$ (sample 3), $40 \mathrm{~s}$ (sample 4), $60 \mathrm{~s}$ (sample 5), and $80 \mathrm{~s}$ (sample 6); and (e) the UST termination points for five separate ingot castings are shown after the melt reached $655^{\circ} \mathrm{C}$ at $1(0 \mathrm{~s}), 2(10 \mathrm{~s}), 3(20 \mathrm{~s}), 4(40 \mathrm{~s})$ and $5(80 \mathrm{~s})$. The cooling curve is from the thermocouple nearest the sonotrode.

\section{Results and discussion}

Source of grains and their transport: As mentioned in the Introduction, the focus of this study is on the effects of acoustic streaming rather than cavitation which is assumed to be occurring under the sonotrode. This means the actual nucleation events have not been studied but their location, the number forming over time, how they are transported throughout the melt and the degree of grain growth that occurs. Figure $2 \mathrm{~b}$ confirms that the main source of equiaxed grains is from the region under the sonotrode (i.e. the cavitation zone). The grain size in this zone is refined (see adjacent microstructure) while outside this zone on the other side of the gauze barrier, large and columnar-like grains are observed. The glycerine-sand analogue of a similar size to the ingot crucible, Figure 2c, shows that the sonotrode generates streaming that causes the liquid to flow vertically downwards. Upon reaching the bottom of the container the melt flows across the bottom and then up the walls of the container generating a circulating flow pattern as this liquid is then sucked into the region under the sonotrode. This observation confirms the simulation results presented in [15]. The sand particles are carried by convection although some particles become lodged in the bottom corners of the container. Figure $2 c$ and simulations in Figure 1 [15] indicate that the newly nucleated grains of the $\mathrm{Al}-2 \% \mathrm{Cu}$ melt will also be forced to move vertically downwards along with any fragmented grains eventually circulating back to the region under the sonotrode and then cirlculated repeatedly until they become mechanically lodge in the corners of the casting cavity. It would be expected that as the number and size of grains increases the size of the mechanically locked regions would become deeper and spread across the bottom and up the walls of the ingot. 
It should be noted that the observations made from these experiments apply to a relatively small ingot. For much larger ingots the velocity of acoustic streaming will gradually decrease with distance from the sonotrode due to attenuation weakening convection. Because the melt is pushed towards the bottom of the ingot, some melt will flow upwards into the cavitation zone maintaining a circulating flow probably in the upper part of the ingot due to the resistance of the melt below. However, it would be expected that as the depth of the ingot increases the decreasing strength of convention may assist many grains of higher density than the liquid to continue sinking to the bottom of the ingot. Depending on the temperature gradient, the settling grains will impede the growth of adjacent grains forming a refined equiaxed microstructure. If a temperature gradient is maintained by heat being extracted though the container walls then a columnar zone could form until stopped by the settling grains as observed for UST of Zn [10].

Evolution of grains: Figures 3a-f show the evolution of grains in the liquid during UST in samples extracted from the melt volume directly under the sonotrode. As the samples were quenched in water immediately after extraction, their microstructure reflects grain formation as UST progresses. The abrupt increase in the cooling rate at the cessation of UST causes large dendrites with fine branches to form during quenching of the remaining liquid as observed in [33]. The small spherical and globular grains (i.e. nondendritic grains) are formed by nucleation and growth during the application of UST. Figure 4 shows the corresponding quantitative relationships between (a) the number of nondendritic grains and (b) their average size versus UST duration after the temperature of the melt reached just below the liquidus temperature $\left(655^{\circ} \mathrm{C}\right)$. Figure $4 \mathrm{a}$ shows that a small number of grains formed in the extracted volume of melt. Note that zero time on the cooling curve (i.e. when the temperature reaches the liquidus temperature) is when the temperature of the thermocouple nearest the sonontrode reaches the liquidus temperature. The actual zero directly under the sonotrode should be when the melt that is extracted reaches the liquidus temperature which will be a few seconds earlier. An estimate of zero time can be made by extending the curves in Figure $4 \mathrm{~b}$ to the $\mathrm{x}$ axis to the left of the y-axis. Depending on the actual steepness of these curves, the start of solidification under the sonotrode would begin at about $-6 \mathrm{~s}$ in relation to the temperature at the thermocouple closest to the cavitation zone of the casting. For clarity during the discussion, the grain size and grain density at $0 \mathrm{~s}$ on the cooling curve corresponds to approximately $6 \mathrm{~s}$ after nucleations begins under the sonotrode. Therefore, reconsidering 
the melt reached the liquidus temperature. Also note that Figure $4 \mathrm{a}$ is not representative of the whole casting but only the area under the sonotrode from where the sample is extracted.

274 Acoustic streaming will quickly sweep these grains into the bulk melt. Each extracted sample 275 is a combination of the grains newly nucleated by the action of the sonotrode and grains that 276 have returned with the circulating melt to a position under the sonotrode one or more times. 277 Thus, a size distribution develops as illustrated by Figure $4 \mathrm{~b}$.

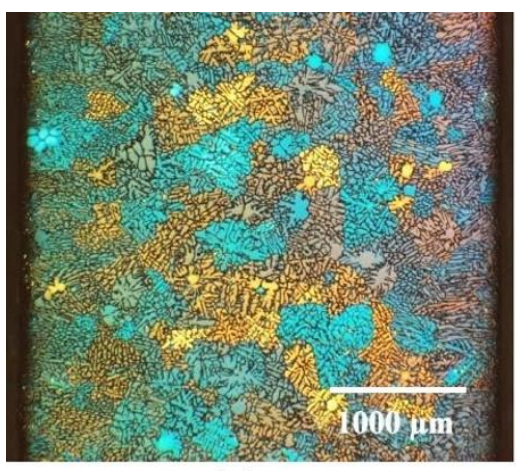

(a)

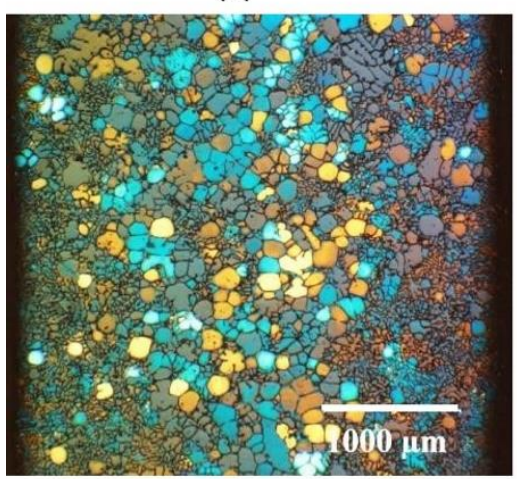

(d)

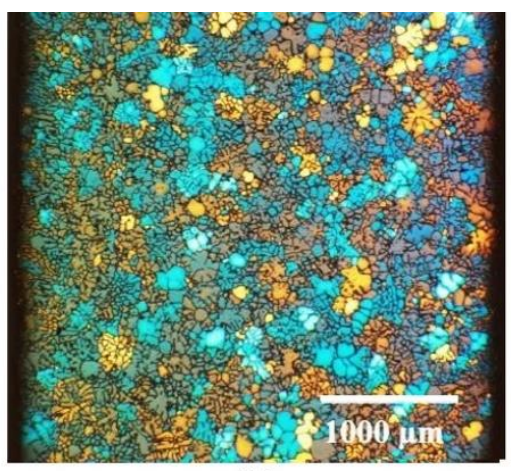

(b)

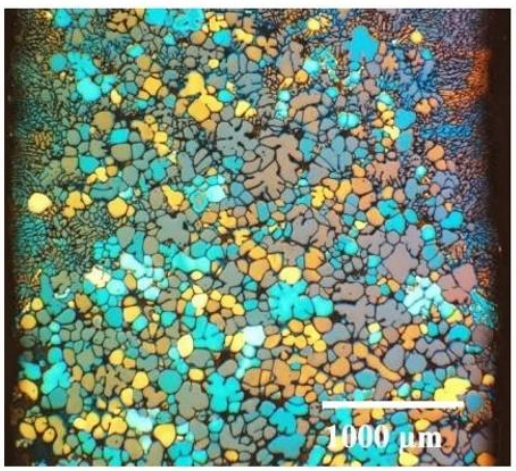

(e)

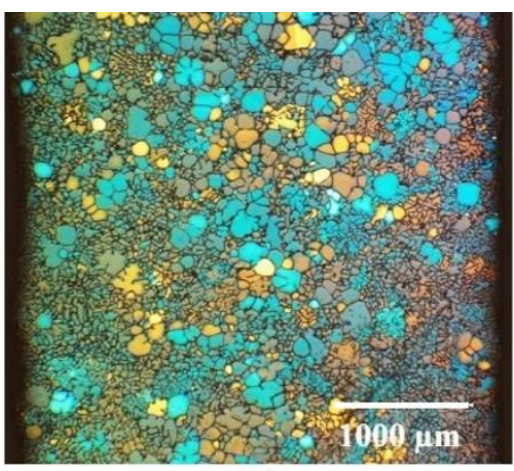

(c)

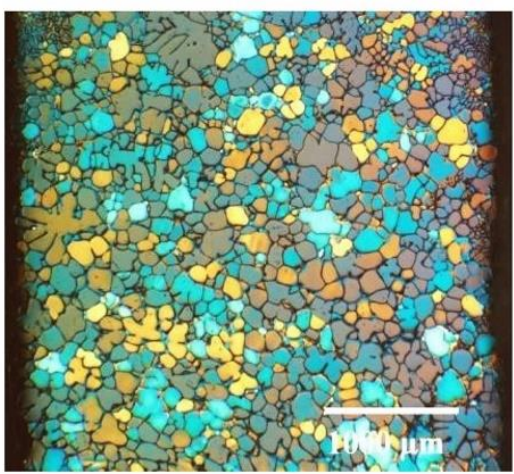

(f)
278

279

280

281

282

283

284

285

286

287

288

289

290

Figure 3. The grain structure of the tube samples taken from the melt during UST after the melt temperature at the thermocouple reached $655^{\circ} \mathrm{C}$ at (a) $0 \mathrm{sec}$, (b) $10 \mathrm{sec}$, (c) $20 \mathrm{sec}$, (d) $40 \mathrm{sec}$, (e) $60 \mathrm{sec}$, and (f) $80 \mathrm{sec}$ (see Figure $2 \mathrm{~d}$ for reference). The larger fine dendritic structure observed in (a) to (e) is formed on quenching of the preheated tube sample extracted from below the sonotrode. The area fraction of these fine dendrites decreases as the number and size of spherical and globular grains increases.

As noted above, the microstructure corresponding to just below the liquidus temperature (Figure 3a) shows only a few small spherical grains. This observation suggests that UST prior to reaching the liquidus temperature does not have a significant impact on the activation of substrates for the nucleation of the primary grains, which is in good agreement with our previous work [16]; and/or that some of the nucleated grains are too small to be observed. Figure $3 \mathrm{~b}$ and Figure $4 \mathrm{a}$ show that the number of spherical nondendritic grains in the 
quenched dendritic matrix approximately doubles during the first $10 \mathrm{~s}$, indicating that continued nucleation occurs during $10 \mathrm{~s}$ of UST. According to Figure $2 \mathrm{~d}$ this period is during recalescence. However, the region under the sonotrode would be beyond the time of recalescence which occurs for about 10s (Figure 2d). With the time increasing from 20 to 40, 60 and $80 \mathrm{~s}$, the number of nondendritic grains increases significantly (Figure 4a) while the grain size begins to stabilize in size after $20 \mathrm{~s}$ as shown in Figure 4b. After $20 \mathrm{~s}$ the distribution of nondendritic grains becomes more and more uniform and after $60 \mathrm{~s}$ a uniform solid network appears to be established, evidenced by interconnected nondendritic grains and porosity formed due to the lack of feed liquid (Figure 3e). Upon continuous application of UST for $80 \mathrm{~s}$ after reaching the liquidus temperature nondendritic grains dominate the microstructure (Figure 3(f)). It is possible that small non-dendritic grains formed during quenching. The maximum number of these grains would be less than 10 grains measured at zero (i.e. $6 \mathrm{~s}$ after the liquidus temperature is reached). Compared to the number of grains measured at subsequent times the quenched grains would have little affect on any conclusions drawn from the data.

Figure $2 \mathrm{~b}$ and the simulation in Figure $1 \mathrm{~b}$ highlight that the new grains are produced in the region under the sonotrode. However, we cannot determine whether some of these grains nucleated on the bottom surface of the sonotrode or all grains were formed by cavitationenhanced heterogeneous nucleation in melt adjacent to this surface. Either mechanism is possible [15, 20].

311

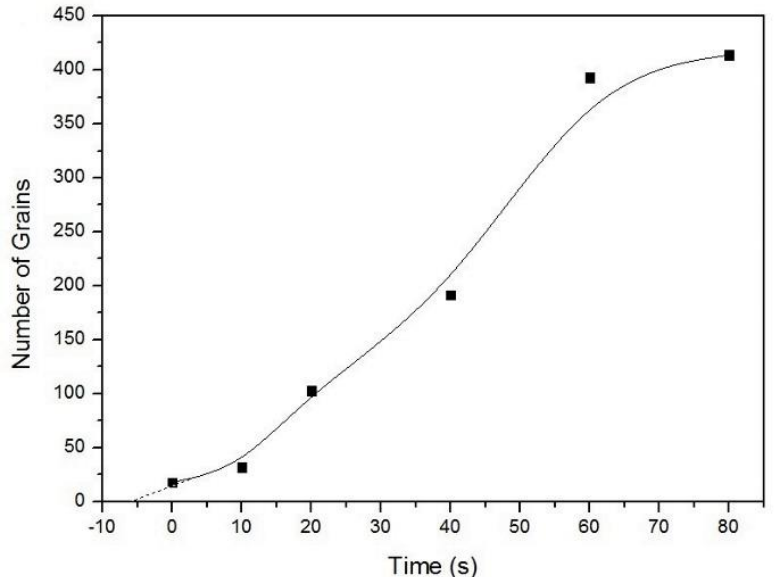

(a)

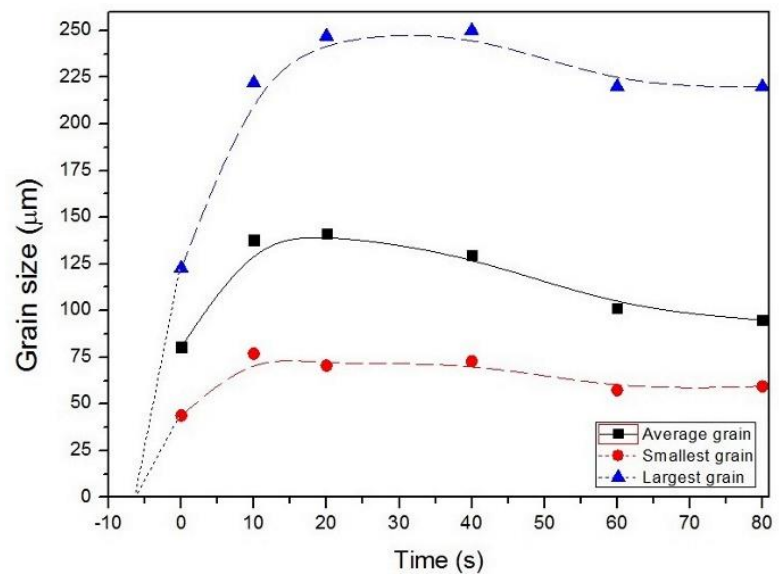

(b)

Figure 4. (a) The total number of spherical/globular nondendritic grains measured in the 
315 spherical/globular grains versus UST duration after the liquidus temperature is reached (see

316 Figure $2 \mathrm{~d}$ for reference).

317 Evolution of macrostructure: Figure 5 shows the macrostructures of the ingots cast without 318 (Figure 5a) and with (Figures 5b-f) UST corresponding to the range of UST termination times 319 marked in Figure 2e. Without UST a fully dendritic grain structure of large grains with rather 320 thick secondary dendrite arms are observed in Figure 5a. In the case of the ingots produced 321 with UST (Figures 5b-f), the vertical cross section of each casting is clearly divided into 322 three regions as indicated by the superimposed boundary lines, i.e. a fine grain region at the bottom and a coarse grain region at the top with a structure similar to that in Figure 5a, and a large columnar grained area at the top of the ingot. The lack of a columnar zone next to the walls and bottom of the ingot and the similar grain size obtained throughout the equiaxed zone indicate that the temperature gradient measured between the two thermocouples extends throughout the melt as predicted by the simulation (Figure 1, [15]). The size of the region of

328 fine equiaxed grains progressively increases with increasing ultrasonication time at the expense of the coarse grained region (Figure 6a). Figure 6b highlights the corresponding regions of grain structure delinieated by dashed lines mapped across the cross section area of Figures $5 \mathrm{~b}-\mathrm{f}$. The grain size in the fine equiaxed region decreases sharply in the first $20 \mathrm{~s}$ of UST with possible slight coarsening occurring afterwards, as illustrated in Figure 7a. Figure $7 \mathrm{~b}$ compares the grain density of the extracted tube samples and the equiaxed zone of the cast ingots showing that the grain densities of both the extracted and ingot samples tend towards the same approximate value. Therefore, UST duration is important for generating a large region of fine equiaxed grains but not necessarily for controlling the grain size in the fine grain region at the bottom. 

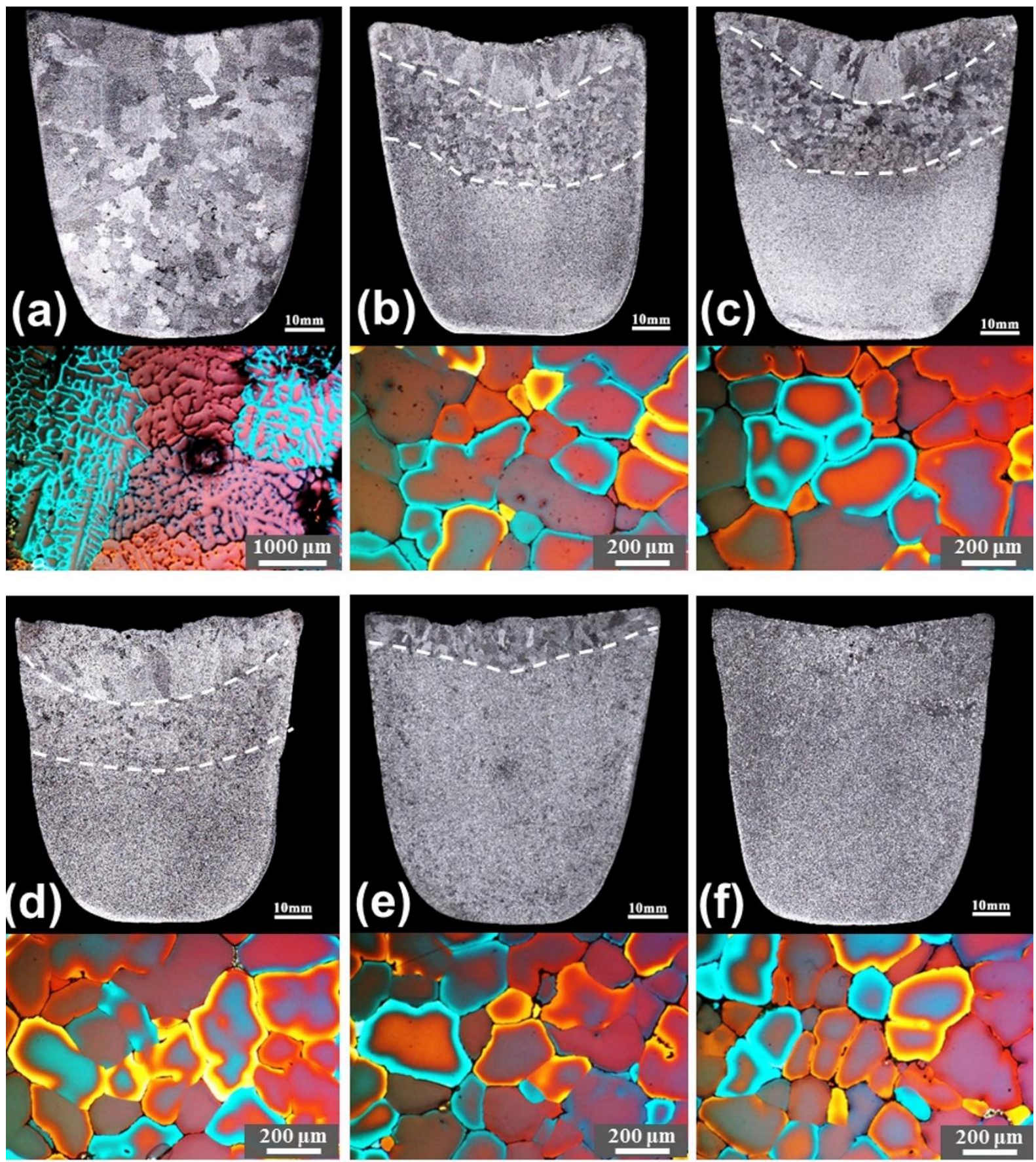

339 Figure 5. Grain structure of the cast ingots (a) without UST, and with UST stopped at (b) $0 \mathrm{~s}$

340 (c) $10 \mathrm{~s} \mathrm{(d)} 20 \mathrm{~s}$ (e) $40 \mathrm{~s}$ and (f) $80 \mathrm{~s}$ (see Figure 2 e for reference) after reaching the liquidus

341 temperature of $655^{\circ} \mathrm{C}$. Note the different scale for the microstructure in $5 \mathrm{a}$. 


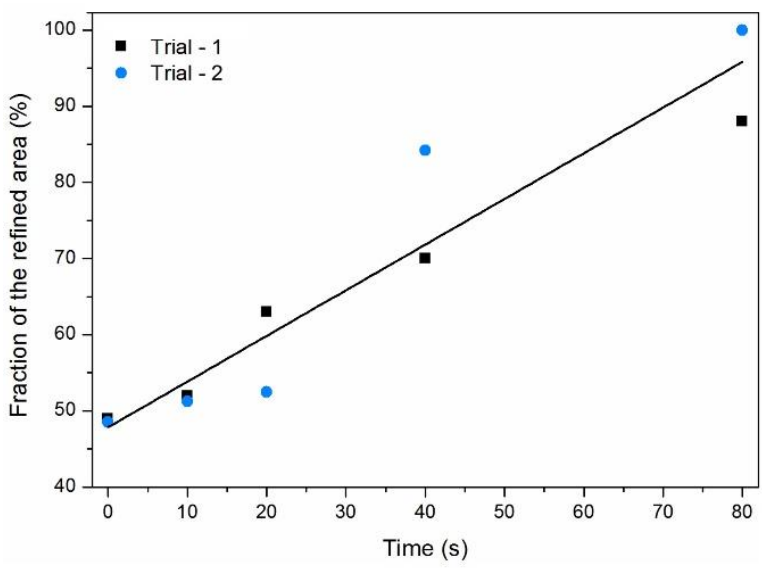

(a)

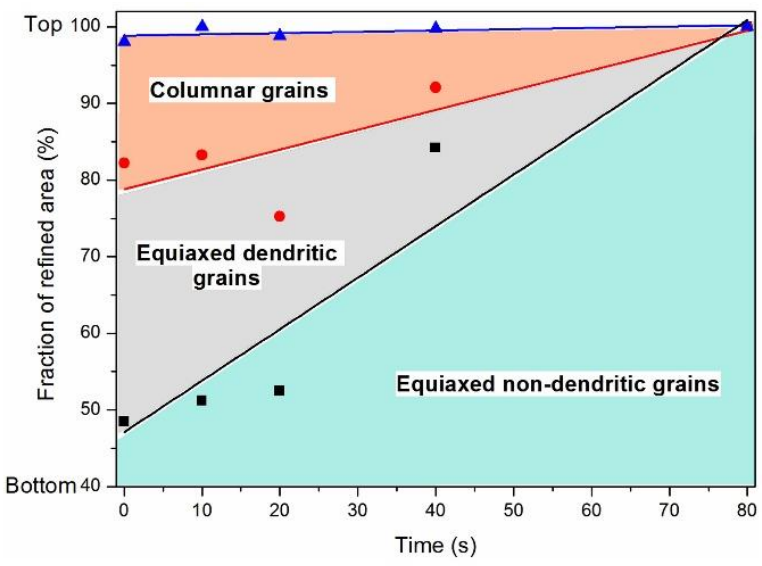

(b)

343 Figure 6. (a) The area fraction of the refined region versus UST duration after the liquidus

344 temperature is reached where each point corresponds to one casting and (b) the corresponding regions of grain structure delinieated by dashed lines mapped across the cross section area of Figures 5 b-f.

In the current study, terminating UST just below the liquidus $\left(655^{\circ} \mathrm{C}\right)$ (i.e. after $0 \mathrm{~s}$ based on the cooling curve but actually after $6 \mathrm{~s}$ under the sonotrode) resulted in grain refinement of about $50 \%$ of the volume, and the grains were refined to about $220 \mu \mathrm{m}$, as shown in Figure 8a. At the same time, only a few small nondendritic grains were observed in the sample taken in situ from under the sonotrode (Figure 3a). The continuously increasing UST duration resulted in a gradual increase in the proportion of refined structure. After 20 to $40 \mathrm{~s}$ of UST the minimum grain size of $140 \mu \mathrm{m}$ is reached. After that time a coherent network of solid grains would begin to form and penetration of the acoustic flow into this region will become hindered. At the same time, the ultrasonic energy is still being supplied to the system, resulting in slower cooling (see the relatively flat cooling curves in Figures $2 \mathrm{~d}$ and e) and possibly grain coarsening as has been reported elsewhere [35]. 


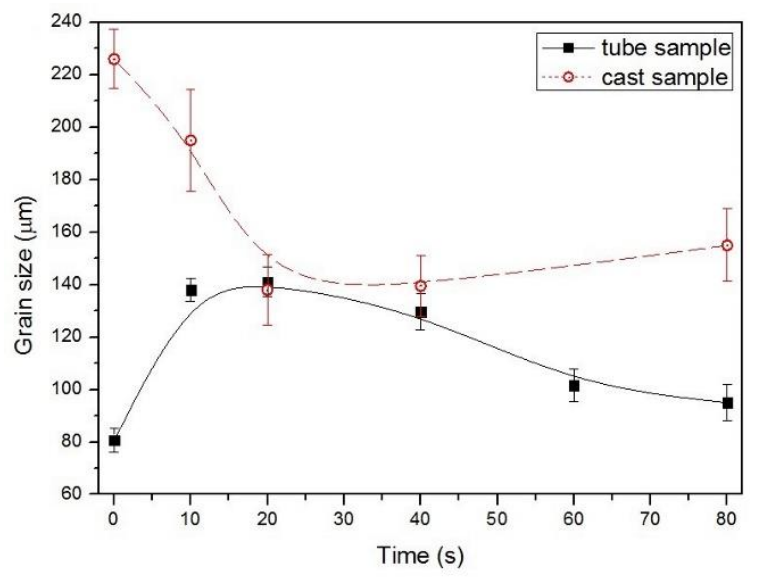

(a)

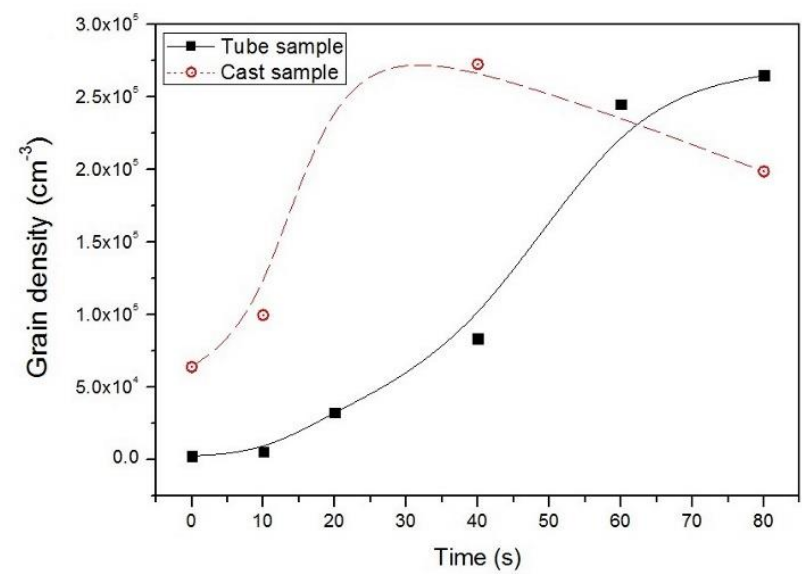

(b)

Figure 7. (a) Grain size comparison between tube samples and the refined equiaxed region of the cast ingots and (b) comparison of grain density between tube samples and ingots versus time.

The combination of refined nondendritic equiaxed grains in the bottom region and coarse dendrites in the upper region of the sample (Figures $4 \mathrm{~b}-\mathrm{e}$ ) can be explained as follows: (1) during the nucleation stage the initially formed and refined grains are generated continuously by UST up to a solid fraction of less than $25 \%$; (2) below $25 \%$ solid fraction and as long as UST continues, the nucleated grains are distributed into the bulk of the melt by acoustic streaming and are kept in suspension and moving, therefore a uniform refined grain structure can be achieved in the refined equiaxed region due to the bulk of the melt being below the liquidus temperature; (3) terminating UST after establishment of the coherent solidified network leads to a fully refined equiaxed grain structure throughout the ingot casting; (4) the unrefined region is formed after termination of UST because the vigorous convection stops and solidification reverts to the case when UST is not applied and large grains are formed in the remaing melt (Figure 5a). Many of the grains present in the melt after termination of UST sink due to the density differential between the liquid and grains depleting the liquid of grains [35] while very few new crystals are generated at this stage of solidification. The grain size in the equiaxed zone is controlled by the amount of growth that occurs while in suspension and by the point during settling when they mechanically contact each other.

The samples taken from below the sonotrode include new grains and grains that are recirculating due to convection. Figure $4 \mathrm{a}$ shows that the number of grains below the sonotrode gradually increase. However, the size range of these particles become more or less constant after about 10 seconds (Figure 4b) despite the number of grains continuing to increase. In the 
extracted samples the rate of increase is about 7 grains per second in the quasi-steady-state regime from 10 to 60 seconds.

386 Figure $4 \mathrm{~b}$ suggests that after $20 \mathrm{~s}$ the size range of grains becomes approximately constant.

387 When the grains mechanically contact each other the rate of settling would cease or 388 dramatically decrease. It would be expected that grains will first collect at the corners and 389 edges of the ingot much like the sand particles in Figure 2c. This implies that there are three 390 zones responsible for the formation of the macrostructure which are illustrated schematically 391 in Figure 8. Zone A is where the grains settle during and after UST is terminated forming a 392 refined equiaxed microstructure. In the melt above Zone A grains continue to move and grow 393 while acoustically-assisted convection continues to be generated. Zone B forms when UST is 394 terminated and the recirculating grains sink into Zone A depleting this Zone of grains 395 allowing the remaining grains to grow larger. Zone $\mathrm{C}$ forms in response to the radient heat 396 cooling the top of the melt such that grains nucleate and grow with a columnar morphology 397 into the melt when the few grains remaining in this region sink into Zone B such that a region 398 of unrefined columnar grains form. 


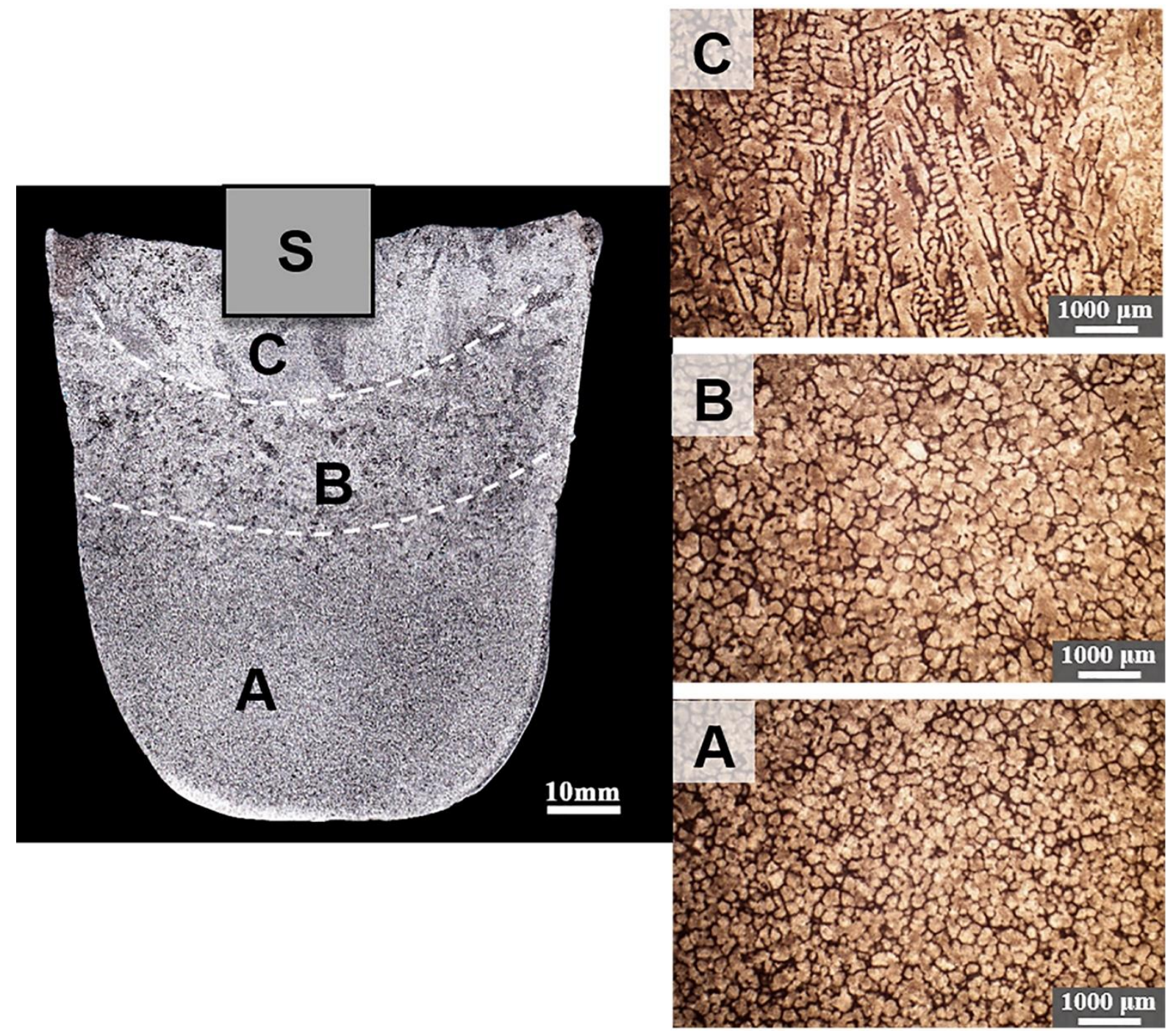

Figure 8. Three distinct zones formed in the macrostructure are identified as A, B and C under a specified duration of ultrasonication after reaching the liquidus $\left(655^{\circ} \mathrm{C}\right)$ of the $\mathrm{Al}-$ $2 \mathrm{wt} . \% \mathrm{Cu}$ alloy. Zone A represents fine equiaxed grains formed during UST that sink to the bottom of the crucible until UST is terminated after 40 seconds. Zone B is depeleted of many of the last to form grains when they sink into Zone A providing more room for growth into larger dendritic or rosette type grains. Zone $\mathrm{C}$ refers to the columnar grains that grow under the influence of the radiant heat transfer from the top surface of the ingot in a region that is unaffected by UST.

\section{The relationship between grain formation and macrostructure development}

Figure 7 allows comparison of the development of, and the relationship between, grain size and grain density between under the sonotrode and in the bulk melt. Figure 7a shows the difference between grain size in the tube samples and the final grain size in the ingots. During the first $20 \mathrm{~s}$ the grain size in the tube samples increases from 80 to $140 \mathrm{~mm}$ while in the 
ingots it decreases from 225 to $140 \mu \mathrm{m}$. This reflects the space available in the melt for grain growth. By referring to Figure $7 b$ the grain density in the tube sample increases slowly while it increases faster in the ingot. Thus, at short times the lower grain density of grains produced can grow over a larger distance until impeded by other grains. As time increases the grain density increases with grains accumulating in the melt reducing the distance between grains such that the average grain size in the ingot decreases. After $20 \mathrm{~s}$ the number density under the sonontrode continues to increase as new grains are formed until the grain density becomes similar to that in the cast ingot. Growth is now severely restricted thus the grain size under the sonotrode decreases indicating that new grains are still being generated. The grain size in the refined equiaxed zone begins to increase slightly possibly due to grain coarsening. However, the size of the error bars suggest there may be little change in grain size after $20 \mathrm{~s}$. The difference in grain density between the equiaxed zone in the ingot and under the sonotrode represents the proportion of grains circulating in the melt that are not recirculated under the sonotrode. Figure 6a shows that the area fraction of the equiaxed zone in the ingots increases steadily from 50 to about $85 \%$. Figure $7 \mathrm{~b}$ shows that the grain density stays about the same after 20 to $30 \mathrm{~s}$ implying that the increase in area fraction of fine equiaxed grains from then on is due to an increase in the number of grains being produced as evidenced by the curve for the tube samples.

Morphology of grains: Due to the imposed agitation the grains mostly remain spherical or globular in morphology with few dendritic grains being observed from their first appearance until $80 \mathrm{~s}$ when UST is terminated. Also, the average grain size remains relatively constant and possibly decreases after $20 \mathrm{~s}$ of UST (Figure $4 \mathrm{~b}$ ). These observations imply that a dendritic morphology does not readily form and, therefore, fragmentation is unlikely to significantly contribute to grain density for this alloy. This conclusion is consistent with the analysis by Kotadia et al. [7] who concluded that fragmentation does not occur in $\mathrm{CP} \mathrm{Al}$ and $\mathrm{Al}-10 \% \mathrm{Cu}$ alloy.

\section{Concluding remarks}

An Al-2Cu alloy was subjected to UST over a range of durations while cooling from $40^{\circ} \mathrm{C}$ above the liquidus temperature to below the liquidus for up to $80 \mathrm{~s}$. The grains that form an equiaxed zone are initially nucleated under the sonotrode. The microstructure of samples extracted from below the sonotrode were compared with the macrostructure on the as-cast ingots. The results are consistent with the predictions of the simulation study [15]: nucleation 
occurs under the cooler sonotrode, a relatively flat temperature gradient forms in the warmer but undercooled bulk melt, and the importance of acoustically-generated convection in forming an equiaxed zone of refined grains.

A number of insights were revealed:

- The cooling curves show that although the temperature fluctuates under UST, the degree of undercooling remains within less than $2{ }^{\circ} \mathrm{C}$ below the liquidus temperature such that the grains can grow in a constitutionally supercooled liquid ensuring the survival of grains while considerable liquid (> 75\%) remains present. The heat generated by the ultrasonic energy would contribute to maintaining a relatively stable temperature range.

- A quasi-steady-state is created under the sonotrode where, within the field of view, seven grains were formed every second from about 20 to $60 \mathrm{~s}$. This process continues as the size of the equiaxed zone increases from about 20 to $85 \%$ of the ingot's cross-sectional area. $40 \mathrm{~s}$ is the optimum time of UST to ensure the finest grain size over the largest area while after $80 \mathrm{~s}$ the largest area of equiaxed grains of a slightly larger size are formed.

- The development of macrostructure over time shows three microstructural zones form with an increasing zone of fine equiaxed grains, a diminishing zone of large globular and dendritic grains, and a zone of columnar grains at the top of the casting. Many of the grains appear to remain in the convective field until UST is terminated after which time they settle towards the bottom of the ingot forming an equiaxed zone. The grain size in the equiaxed zone is set by the density of settling grains. Initially, an increasing grain density contributes to an increased size of the equiaxed zone. After about 20s, continued application of UST does not increase the grain density but the number of grains generated over time continues to increase which in turn increases the area fraction of the refined equiaxed zone up to $85 \%$. After $80 \mathrm{~s}$ the zones of larger globular, dendritic and columnar grains are surpressed while the fine equiaxed zone fills the macrostructure.

- Grain size is controlled by the number of grains present in the melt and the time available for settling. Thus, few grains produced at shorter times grow to a larger size than when, after a longer time, many grains have formed with comparatively limited space left to grow.

- The new grains initially form with a spherical morphology. The morphology becomes globular with some dendritic grains present after $80 \mathrm{~s}$ of UST. The globular morphology is maintained by the vigorous convection circulating in the ingot. 
- The observation of mostly spherical and globular grains throughout the application of UST indicates that fragmentation is not a significant source of additional grains during UST of an Al-2Cu alloy. The fully dendritic grains observed in the tube samples and the large grains above the equiaxed zone are formed when UST is terminated either by quenching or cooling in air.

\section{Acknowledgements}

The authors gratefully acknowledge financial support from the Defence Materials Technology Center (DMTC) which was established, and supported by the Australian Government's Defence Future Capability Technology Centres Programme, the Australian Research Council grant DP140100702, and the ExoMet Project co-funded by the European Commission's 7th Framework Programme (contract FP7-NMP3-LA-2012-280421), by the European Space Agency and by the individual partner organizations.

\section{References}

[1] G.I. Eskin: Ultrasonic Treatment of Light Alloy Melts, Gordon and Breach Science Publishers, Amsterdam, 1998.

[2] O.V. Abramov: Ultrasound in Liquid and Solid Metals, CRC press, Boca Raton, FL, 1994.

[3] G.I. Eskin and D.G. Eskin: Ultrasonic Treatment of Light Alloy Melts. $2^{\text {nd }}$ ed., : CRC Press, Boca Raton, FL, 2014, pp. 129-170.

[4] Y. Ozawa, X. Liu, S. Takamori, H. Somekawa, and T. Mukai: Materials Transactions, 2008, vol. 49, pp. 972-975.

[5] T.V. Atamanenko, D.G. Eskin, L. Zhang, and L. Katgerman: Metallugical and Materials Transactions A, 2010, vol. 41, pp. 2056-2066.

[6] N. Srivastava, G.P. Chaudhari, M.Qian: Journal of Materials Processing Technology, 2017, vol. 249, pp. 367-378.

[7] H.R. Kotadia, M. Qian, D.G. Eskin, A. Das: Materials \& Design, 2017, vol. 132, pp. 266-274.

[8] Q. Liu, Q. Zhai, F. Qi, and Y. Zha: Materials Letters, 2017, vol. 61, pp. 2422-2425.

[9] J. Kang, X. Zhang,Y. Hu, J. Ma, Y. Hu and T. Huang: ISIJ International, 2014, vol. 54, pp. 281-287.

[10] B. Nagasivamuni, G. Wang, D.H. StJohn, M.S. Dargusch: Journal of Crystal Growth, 2018, vol. 495, pp. 20-28. 
[11] R. Chen, D. Zheng, T. Ma, H. Ding, Y. Su, J. Guo, H. Fu: Scientific Reports, 2017, vol. $7,41463$.

[12] D. Ensminger and L.J. Bond: Ultrasonics: Fundamentals, Technologies, and Applications, $3^{\text {rd }}$ ed., CRC Press, Boca Raton, FL, 2012.

[13] Juan A. Gallego-Juárez and Karl F. Graff, Power ultrasonics : applications of highintensity ultrasound, Woodhead Publishing Ltd, Waltham, Massachusetts, 2015.

[14] Y. Ishiwata, S. Komarov, and Y. Takeda: Proc. $13^{\text {th }}$ International Conference on Aluminum Alloys (ICAA13), eds. H. Weiland, A.D. Rollett, W.A. Cassada, Warendale: TMS (The Minerals, Metals \& Materials Society), 2012, pp. 183-188.

[15] G. Wang, P. Croaker, M. Dargusch, D. McGuckin and D. StJohn: Computational Materials Science, 2017, vol. 134, pp. 116-125.

[16] M.C. Schenker, MJBM Pourquie, D.G. Eskin, B.J. Boersma: Ultrasonics Sonochemistry, 2013, vol. 20, pp. 502-509.

[17] G.S.B. Lebon, G. Salloum-Abou-Jaoude, D. Eskin, I. Tzanakis, K. Pericleous, P. Jarry: Ultrasonics Sonochemistry, 2019, vol. 54, pp. 171-182.

[18] G.S.B. Lebon, I. Tzanakis, K. Pericleous, D. Eskin, P.S. Grant: Ultrasonics Sonochemistry, 2019, vol. 55, pp.243-255.

[19] Takuya Yamamoto and Sergey Komarov: Light Metals, 2019, pp. 1527-1531.

[20] G. Wang, M.S. Dargusch, M. Qian, D.G. Eskin, and D.H. StJohn: Journal of Crystals Growth, 2014, vol. 408, pp. 119-124.

[21] G. Wang, M.S. Dargusch, M. Qian, D.G. Eskin, and D.H. StJohn: Advanced Engineering Materials, 2018, 1800521, pp. 1-12.

[22] J. Lighthill: Journal of Sound Vibration, 1978, vol. 61, pp. 391-418.

[23] D.H. StJohn, A. Prasad, M.A. Easton, M. Qian: Metallurical and Materials Transactions A, 2015, vol. 46, pp. 4868-4885.

[24] G. Chai, L. Backerud, T. Rolland, L. Arnberg: Metallurical and Materials Transactions A, 1995, vol. 26, pp. 965- 976.

[25] T. Sumitomo, D.H. StJohn, T. Steinberg: Materials Science and Engineering A, 2000, vol. 289, pp. 18-19.

[26] B. Nagasivamuni, G. Wang, D.H. StJohn, M.S. Dargusch: In: Corleen Chesonis, Light Metals 2019, Light Metals Symposium, TMS Annual Meeting and Exhibition, San Antonio, TX, United States, 10-14 March 2019, pp. 1579-1586.

[27] J. Hutt \& D. StJohn: International Journal of Cast Metals Research, 1998, vol. 11, pp. 13-22. 
544 [28] A. Ohno: The Solidification of Metals, Chijin Shokan Co., Tokyo, 1976.

545 [29] A.Ohno: Solidification - The Separation Theory and its Practical Applications, Springer-

546 Verlag, Berlin Heidelberg New York London Paris Tokyo, 1987

547 [30]Z. Yin, D. Liang, Y. Chen, Y. Cheng, Q. Zhai: Trans. Nonferrous Metals Soc. China, $548 \quad$ 2013, vol. 23, pp. 92-97.

549 [31] Y.J. Li, W.Z. Tao, Y.S. Yang: J. Mater. Process. Technol., 2012, vol. 212, pp. 903-909.

550 [32] I. Tzanakis, G.S.B Lebon, D. Eskin, K. Pericleous: Ultrasonics Sonochemistry, 2017, $551 \quad$ vol. 34 , pp. 651-662.

552 [33] S.D. McDonald, K. Nogita, A.K. Dahle: Acta Materitalia, 2004, vol. 52, pp. 4273-4280.

553 [34] J. Hirsch, B. Skrotzki, G. Gottstein: Aluminium Alloys: Their Physical and Mechanical 554 Properties (ICAA11), Wiley-VCH, Weinheim, 2008, pp. 316-320.

555 [35] A. Prasad, E. Liotti, S.D. McDonald, K. Nogita, H. Yasuda, P.S. Grant and D.H. StJohn: $556 \quad$ IOP Conference Series: Materials Science And Engineering, 2015, vol. 84, 012014, pp. $1-9$. 